\title{
Front Matter: Volume 10722
}

, "Front Matter: Volume 10722," Proc. SPIE 10722, Plasmonics: Design, Materials, Fabrication, Characterization, and Applications XVI, 1072201 (2 November 2018); doi: 10.1117/12.2515560

SPIE Event: SPIE Nanoscience + Engineering, 2018, San Diego, California, United SPIE. States 


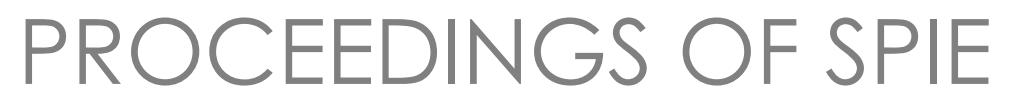

\section{Plasmonics: Design, Materials, Fabrication, Characterization, and Applications XVI}

Din Ping Tsai

Takuo Tanaka

Editors

19-23 August 2018

San Diego, California, United States

Sponsored and Published by

SPIE

Volume 10722 
The papers in this volume were part of the technical conference cited on the cover and title page. Papers were selected and subject to review by the editors and conference program committee. Some conference presentations may not be available for publication. Additional papers and presentation recordings may be available online in the SPIE Digital Library at SPIEDigitalLibrary.org.

The papers reflect the work and thoughts of the authors and are published herein as submitted. The publisher is not responsible for the validity of the information or for any outcomes resulting from reliance thereon.

Please use the following format to cite material from these proceedings:

Author(s), "Title of Paper," in Plasmonics: Design, Materials, Fabrication, Characterization, and Applications XVI, edited by Din Ping Tsai, Takuo Tanaka, Proceedings of SPIE Vol. 10722 (SPIE, Bellingham, WA, 2018) Seven-digit Article CID Number.

ISSN: 0277-786X

ISSN: 1996-756X (electronic)

ISBN: 9781510620155

ISBN: 9781510620162 (electronic)

Published by

SPIE

P.O. Box 10, Bellingham, Washington 98227-0010 USA

Telephone +1 3606763290 (Pacific Time) · Fax +1 3606471445

SPIE.org

Copyright (C) 2018, Society of Photo-Optical Instrumentation Engineers.

Copying of material in this book for internal or personal use, or for the internal or personal use of specific clients, beyond the fair use provisions granted by the U.S. Copyright Law is authorized by SPIE subject to payment of copying fees. The Transactional Reporting Service base fee for this volume is $\$ 18.00$ per article (or portion thereof), which should be paid directly to the Copyright Clearance Center (CCC), 222 Rosewood Drive, Danvers, MA 01923. Payment may also be made electronically through CCC Online at copyright.com. Other copying for republication, resale, advertising or promotion, or any form of systematic or multiple reproduction of any material in this book is prohibited except with permission in writing from the publisher. The CCC fee code is 0277$786 \mathrm{X} / 18 / \$ 18.00$.

Printed in the United States of America.

Publication of record for individual papers is online in the SPIE Digital Library.

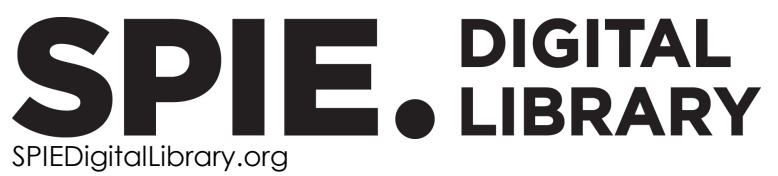

Paper Numbering: Proceedings of SPIE follow an e-First publication model. A unique citation identifier (CID) number is assigned to each article at the time of publication. Utilization of CIDs allows articles to be fully citable as soon as they are published online, and connects the same identifier to all online and print versions of the publication. SPIE uses a seven-digit CID article numbering system structured as follows:

- The first five digits correspond to the SPIE volume number.

- The last two digits indicate publication order within the volume using a Base 36 numbering system employing both numerals and letters. These two-number sets start with $00,01,02,03,04$, 05, 06, 07, 08, 09, 0A, OB ... 0Z, followed by 10-1Z, 20-2Z, etc. The CID Number appears on each page of the manuscript. 


\title{
Contents
}

\author{
vii Authors \\ ix Conference Committee \\ xiii Introduction
}

QUANTUM PLASMONICS

10722 OA Revisiting quantum optics with single plasmons (Invited Paper) [10722-7]

10722 OB Quantum hydrodynamics for nanoplasmonics [10722-8]

PLASMONIC APPLICATIONS I

10722 OE Coherent superresolution assisted by surface plasmons and the role of dielelctric microlenses (Invited Paper) [10722-12]

PLASMONIC APPLICATIONS II

$107220 \mathrm{~J} \quad$ Broadband enhancement of quantum dot emission for microLED using Ag plasmonic nanoparticles [10722-17]

METASURFACE

1072200 Plasmonic coupled modes in metal-insulator-metal structures for sensing applications (Invited Paper) [10722-22]

FUNDAMENTAL OF PLASMONICS I

10722 OP Nanophotonic structures for highly efficient on-chip optical manipulation (Invited Paper) [10722-23] 
ACTIVE CONTROL

1072216 Plasmonic vanadium dioxide microbolometers with wavelength and polarisation sensitivity [10722-40]

PLASMONIC SENSING II

10722 iP Multispectral SERS using plasmonic width-graded nanogratings [10722-60]

NONLINEAR II

10722 IR Nonlinear graphene metasurfaces with advanced electromagnetic functionalities (Invited Paper) [10722-62]

\section{PLASMONIC APPLICATIONS V}

$107221 \mathrm{U}$ Second harmonic generation dynamics in plasmonic nanoparticles [10722-65]

\section{POSTER SESSION}

1072212 Graphene-coated nanowires with a drop-shaped cross section for both the strong mode confinement and the long-range propagation [10722-70]

1072220 Ultra-compact optical switch based on Fano resonance in graphene-functionalized plasmonic nano-cavity [10722-71]

1072223 Oxygen deficiencies and optical absorption in hexagonal tungsten bronze nanoparticles [10722-74]

1072224 Sensitivity enhancement of surface plasmon resonance biosensor with graphene sandwiched between two metal films [10722-75]

1072225 Plasmonic-induced transparency in a MIM waveguide with two side-coupled rectangular ring disk structures [10722-76]

10722 2B Coupling light into silicon waveguides using surface plasmon polaritons [10722-82]

$107222 \mathrm{E} \quad$ Vibrational overtones spectroscopy enabled by plasmonic nanoantennas [10722-85]

$10722 \mathrm{2L} \quad$ Optical modeling and computational analysis of tapered dome shaped nanoantenna [10722-92] 
Design and analysis of a hollow bowtie nanoantenna [10722-93]

10722 2N Solar-matched broadband (400-1400 nm) plasmonic absorbing inks [10722-94]

1072220 UV-nil based fabrication of plasmon-magnetic nanoparticles for biomolecular sensing [10722-95]

$107222 \mathrm{R} \quad$ Localized surface plasmons on periodic monolayer black phosphorene nanoribbons tuned in the infrared region with a dielectric substrate [10722-98]

10722 2V Analysis of filtering and lasing characteristic using plasmonic nanogap resonance effect [10722-102]

$107222 \mathrm{X}$ Investigation of nanoplasmonic antenna for increased performance of high temperature operation PbSe photoconductors [10722-105]

$107222 \mathrm{Y}$ A simulation study of plasmonic resonance in nanosandwich structures of noble metals in optical range [10722-106]

1072230 Broadband polarization-independent absorber based on multilayered metamaterial [10722-109]

1072231 Asymmetrical absorption in plasmonic devices optimized by genetic algorithms [10722-110]

1072234 Simulation of absorption spectra of Au/PTFE nanocomposite by means Maxwell-Garnett effective medium approximation [10722-116] 
Proc. of SPIE Vol. 10722 1072201-6

Downloaded From: https://www.spiedigitallibrary.org/conference-proceedings-of-spie on 25 Apr 2023 Terms of Use: https://www.spiedigitallibrary.org/terms-of-use 


\title{
Authors
}

Numbers in the index correspond to the last two digits of the seven-digit citation identifier (CID) article numbering system used in Proceedings of SPIE. The first five digits reflect the volume number. Base 36 numbering is employed for the last two digits and indicates the order of articles within the volume. Numbers start with 00, 01, 02, 03, 04, 05, 06, 07, 08, 09, OA, OB...0Z, followed by 10-1Z, 20-2Z, etc.

\author{
Adachi, Kenji, 23 \\ Alsheheri, Soad, $2 Y$ \\ Andam, N., 00 \\ Argyropoulos, Christos, $1 R$ \\ Bauman, Stephen J., 2R \\ Bernasconi, Gabriel D., $1 \mathrm{U}$ \\ Brückl, Hubert, 20 \\ Butet, Jérémy, $1 \mathrm{U}$ \\ Chang, Chih-Wei, OE \\ Cheng, L.-J., OJ \\ Chu, Shi-Wei, OE \\ Cong, Xuan, 12 \\ Dadadzhanov, Daler R., 2E \\ Debu, Desalegn T., 2R \\ Deol, Rajinder Singh, 2N \\ Devaux, Eloïse, OA \\ Dham, Jorawar Singh, 2L \\ Dheur, Marie-Christine, OA \\ Dixon, K., $1 \mathrm{P}$ \\ Du, Wei, 24, 25 \\ Fang, Xu, 16 \\ Frame, James D., 16 \\ Franco Rego, Davi, 31 \\ French, David, 2R \\ Gautam, Lakshay, 2L \\ Gomes de Souza, I. L., 30 \\ Goyal, Parul, 2M \\ Grayer, Justin, 2X \\ Green, Nicolas G., 16 \\ Greffet, Jean-Jacques, OA \\ Ha, Heonhak, 20 \\ Haslinger, Michael, 20 \\ Hayasi, S., $0 O$ \\ Hervieux, Paul-Antoine, OB \\ Herzog, Joseph B., 2R \\ Hong, Youngsun, 2V \\ Huang, Yingxue, $1 Z$ \\ Hugonin, Jean-Paul, OA \\ Inouye, $Y_{\text {., }} 0 \mathrm{O}$ \\ Ishitobi, H., $0 \mathrm{O}$ \\ Jang, Min Seok, 20 \\ Jiao, Kunpeng, 24, 25 \\ Jiao, Lipeng, 24, 25 \\ Jin, Boyuan, $1 \mathrm{R}$ \\ Kalra, Yogita, 2M \\ Kannegulla, A., OJ \\ Karabchevsky, Alina, 2E \\ Kazemi-Zanjani, N., IP \\ Kherani, N. P., IP
}

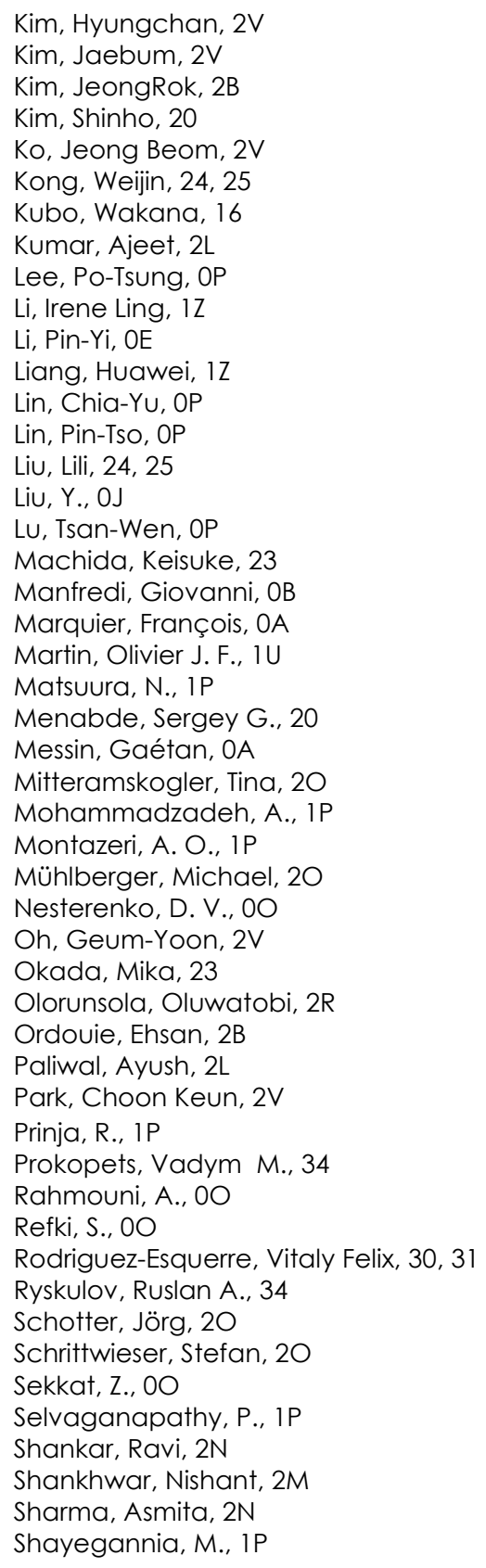


Sheng, Yulin, 25

Shlesinger, llan, OA

Shoshi, Astrit, 20

Siahmakoun, Azad, 2B

Singh, Madhusudan, 2N

Su, Hong, $1 \mathrm{Z}$

Tanjia, Fatema, OB

Tsai, Chia-Yang, OP

Tsao, Yang, OE

Vartanyan, Tigran A., 2E

Vest, Benjamin, OA

Walia, Anmol, 2N

Wang, Mei, 24, 25

Wang, Y.-C., OJ

Wu, B., OJ

Wu, Di, 24, 25

Xia, Feng, 24, 25

Yablochkova, Kateryna S., 34

Yang, Young Jin, 2V

Yoo, Sung-Shik, $2 X$

Yun, Maojin, 24, 25

Zavodni, A., IP

Zhang, Min, $1 Z$

Zhu, S., IP 


\title{
Conference Committee
}

\author{
Symposium Chairs
}

Halina Rubinsztein-Dunlop, The University of Queensland (Australia)

Mark L. Brongersma, Geballe Laboratory for Advanced Materials

(GLAM), Stanford University (United States)

Symposium Co-chairs

Harry A. Atwater Jr., California Institute of Technology (United States)

Nikolay I. Zheludev, Optoelectronics Research Centre

(United Kingdom) and Nanyang Technological University

(Singapore)

Conference Chairs

Din Ping Tsai, National Taiwan University (Taiwan)

Takuo Tanaka, RIKEN Center for Advanced Photonics (Japan)

\section{Conference Program Committee}

Martin Aeschlimann, Technische Universität Kaiserslautern (Germany)

Harry A. Atwater Jr., California Institute of Technology (United States)

David J. Bergman, Tel Aviv University (Israel)

Allan D. Boardman, University of Salford (United Kingdom)

Che Ting Chan, Hong Kong University of Science and Technology

(Hong Kong, China)

Yun-Chorng Chang, Academia Sinica (Taiwan)

Harald W. Giessen, Universität Stuttgart (Germany)

Jean-Jacques Greffet, Institut d'Optique Graduate School (France)

Naomi J. Halas, Rice University (United States)

Martti Kauranen, Tampere University of Technology (Finland)

Dai-Sik Kim, Seoul National University (Korea, Republic of)

Laurens K. Kuipers, FOM Institute for Atomic and Molecular Physics

(Netherlands)

Mikhail Lapine, The University of Sydney (Australia)

Ai Qun Liu, Nanyang Technological University (Singapore)

Olivier J. F. Martin, Ecole Polytechnique Fédérale de Lausanne

(Switzerland)

Peter Nordlander, Rice University (United States)

Lukas Novotny, University of Rochester (United States)

George C. Schatz, Northwestern University (United States)

Tigran V. Shahbazyan, Jackson State University (United States) 
Vladimir M. Shalaev, Purdue University (United States)

Gennady B. Shvets, Institute for Fusion Studies (United States)

Niek F. van Hulst, ICFO - Institut de Ciències Fotòniques (Spain)

Hongxing Xu, Wuhan University (China)

Nikolay I. Zheludev, Optoelectronics Research Centre

(United Kingdom) and Nanyang Technological University

(Singapore)

\section{Session Chairs}

1 Novel Materials for Plasmonics

Din Ping Tsai, Research Center for Applied Sciences - Academia Sinica (Taiwan)

2 Characterization for Plasmonics

Takuo Tanaka, RIKEN Center for Advanced Photonics (Japan)

3 Quantum Plasmonics

Dong Ha Kim, Ewha Womans University (Korea, Republic of)

4 Plasmonic Applications I

Dana-Codruta Marinica, Institut des Sciences Moléculaires d'Orsay (France)

5 Plasmonic Applications II

Hui-Hsin Hsiao, Taipei Medical University (Taiwan)

6 Metasurface

Kyoko Namura, Kyoto University (Japan)

7 Fundamental of Plasmonics I

Cheng Hung Chu, Research Center for Applied Sciences - Academia Sinica (Taiwan)

8 Nonlinear I

Olivier J. F. Martin, Ecole Polytechnique Fédérale de Lausanne (Switzerland)

9 Plasmonic Sensing I

Jeongyong Kim, Sungkyunkwan University (Korea, Republic of)

10 Radiation Engineering

Yu-Ju Hung, National Sun Yat-sen University (Taiwan) 
11 Active Control

Takuo Tanaka, RIKEN Center for Advanced Photonics (Japan)

Yu-Jung Lu, Research Center for Applied Sciences - Academia Sinica (Taiwan)

12 Fundamental of Plasmonics II

Yu-Jung Lu, Research Center for Applied Sciences - Academia Sinica (Taiwan)

13 Chiral Plasmonics

Martti Kauranen, Tampere University of Technology (Finland)

14 Plasmonic Applications III

Laurens Kobus Kuipers, Kavli Institute of Nanoscience Delft (Netherlands)

15 Plasmonic Applications IV

Yao-Wei Huang, Harvard University (United States)

16 Plasmonic Sensing II

Cheng Hung Chu, Research Center for Applied Sciences - Academia Sinica (Taiwan)

17 Nonlinear II

Wakana Kubo, Tokyo University of Agriculture and Technology (Japan)

18 Plasmonic Applications $V$

Pin Chieh Wu, Caltech (United States) 
Proc. of SPIE Vol. 10722 1072201-12 Downloaded From: https://www.spiedigitallibrary.org/conference-proceedings-of-spie on 25 Apr 2023
Terms of Use: https://www.spiedigitallibrary.org/terms-of-use 


\section{Introduction}

This proceedings volume contains the papers presented at the 2018 SPIE Optics + Photonics conference on Plasmonics: Design, Materials, Fabrication, Characterization, and Applications XVI held in San Diego, California, 19-23 August 2018. The aim of the conference was to bring together specialists from diverse research areas and to provide a forum for the exchange of information on the latest progress of the plasmonics.

The conference was divided into 18 sessions, covering a variety of topics related to the plasmonics. In the first session, presentations were related to novel materials for plasmonics, such as ultra-thin transition metal nitrides for tailorable plasmonic devices; metamaterial infrared absorber with nanofluidic channel for ultrasensitive molecular detection; tunable plasmon-induced resonance energy transfer and plasmon-exciton coupling in single plasmonic nanoparticles on two-dimensional transition metal dichalcogenides; plasmon-assisted cooperative energy transfer controls spontaneous emission rate beyond field enhancement limits; and plasmons at the interface for physics and medicine.

The second session was related to characterization for plasmonics, including the solar cell based on metamaterial perfect absorber; and novel nanospectroscopic technique through tip-enhanced Raman spectroscopy.

The third session dealt with plasmonic applications: revisiting quantum optics with single plasmons; quantum hydrodynamics for nanoplasmonics; and quantum effects in nanogap plasmonic systems.

The fourth session was quantum plasmonics, including plasmon-enhanced multifunctions; and the role of dielectric microlenses.

The fifth session was on plasmonic applications as well, such as microbubble nucleation and subsequent flow generation studied by thermoplasmonic effect; conversion and inversion of plasmonic angular momenta in nano-space; broadband enhancement of quantum dot emission for microLED using UV plasmonic nanoparticles; and plasmonic resonator devices for integrated application.

The sixth session's topic was metasurface, including broadband achromatic and high efficient metadevices via aluminum integrated resonant unit of metasurfaces; broadband plasmonic detour phase meta-holograms with full parameter control of light; high efficiency full-color router based on GaN metalens; and plasmonic coupled modes in metal-insulator-metal structures for sensing application.

The seventh session was devoted to fundamental of plasmonics, including nanophotonic structures for highly efficient on-chip optical manipulation; 
observation of pure magnetism at optical frequencies in a plasmonic system; generation of convergent light spot by surface plasmon manipulated Smith-Purcell radiation on Yagi-Uda nanoantenna arrays; and avoided resonance crossing and asymmetric nearly perfect absorption in plasmonic nanodisks with near-field and far-field couplings.

The eighth session was related to nonlinear, including manifestations of photon acceleration in semiconductor metasurfaces; hybrid plasmonic-dielectric metamaterials for enhanced nonlinear response; and nano-optics of single plasmonic particle-on-film nanocavities.

The ninth session was also about plasmonic sensing: the enhancement of biomolecular detecting in Bloch surface wave sensor; and fluorescence of Pt nanoclusters for bio-imaging.

The tenth session was radiation engineering: exciton-plasmon interaction in twodimensional semiconductors for refined light emission; a virus assembly experimental approach to the plasmonic Dicke effect; all-round fluorescence enhancements using Ag-Si hybrid stack nanoantennas; configurable strong coupling within plasmonic junctions; and deconvolving excitons and free carriers using plasmonic emission enhancement effect.

The eleventh session was active control. We had papers presented on ultra-lowloss polaritons in hexagonal boron nitride; active control of plasmonic enhanced light emission: tunable spontaneous emission and new plasmonic lasers; plasmonic vanadium dioxide microbolometers with wavelength and polarisation sensitivity; graphene-based plasmon modulator on silicon; and dynamic polarization control with optical metasurfaces.

The twelfth session was fundamental of plasmonics as well, which included excitedstate and correlated light-matter interactions; a Van Hove singularity in the topology critical point of bilayer hyperbolic metamaterials; and towards the observation of exceptional points (EPS) in passive plasmonic nanostructures.

The thirteenth session was chiral plasmonics: nanoscale chiral valley-photon interface; peptide encoded gigantic chirality evolution in three-dimensional plasmonic helicoids; disordered photonic metasurfaces for complex light field control; and enhancing chiral fields with arrays of achiral particles.

The fourteenth session was plasmonic applications as well: thermal radiation studies of plasmonic materials and single antennas; additive nanomanufacturing of metallic nanostructures through a kick-and-place approach; and plasmonic angular momentum and its dynamical interactions with electrons.

The fifteenth session was also related to plasmonic applications, including nanoscale imaging of optical field by electron microscopy; super-resolution 
mapping of the local density of states with single-molecule and fluorescence lifetime imaging microscopy; and direct measurement of optical losses in plasmonenhanced thin silicon films.

The sixteenth session was devoted to plasmonic sensing as well, such as tunable plasmonic Moiré chiral metamaterials: cost-effective fabrication; and ultrasensitive SERS using plasmonic width-graded nanogratings.

The seventeenth session was also focused on nonlinear. We had papers presented on collective nonlinear optical effects in plasmonic oligomers using cylindrical vector beams; nonlinear graphene metasurfaces with advanced electromagnetic functionalities; and opto-acoustic interactions in lossy metal-dielectric waveguides.

The eighteenth session was also related to plasmonic applications, including plasmonic approaches for visualizing and controlling intercalation-driven phase transformations; second harmonic generation dynamic in plasmonic nanoparticles; absorption enhancement of dielectric metasurfaces with the Kerker effect; and large-scale chiral nanostructures fabricated using high-throughput nanofabrication methods.

Din Ping Tsai Takuo Tanaka 
Proc. of SPIE Vol. 10722 1072201-16

Downloaded From: https://www.spiedigitallibrary.org/conference-proceedings-of-spie on 25 Apr 2023 Terms of Use: https://www.spiedigitallibrary.org/terms-of-use 